\title{
Malignancy in chronic ulcers in leprosy: a report of 5 cases from Northern Nigeria
}

\author{
N B B REDDY,* T SRINIVASAN, * S A R KRISHNAN* \\ \& S R BHUSNURMATH \\ * Leprosy Control Research and Training Centre, Zaria, Nigeria; \\ $\dagger$ Department of Human Pathology, Ahmadu Bello University, \\ Zaria, Nigeria
}

Accepted for publication 11 October 1984

Summary Five patients, 2 of the usual varicty of squamous cell carcinoma and 3 of verrucous carcinoma are reported. Four patients had BT type of leprosy and I had LL type of leprosy. Interestingly, one of the verrucous carcinomas occurred over the palm which is a rare sitc.

\section{Introduction}

Published accounts of malignant change in leprosy ulcers are rare and the literature records mostly case reports. In a brief period of 2 years, 5 such patients were detected at the Leprosy Control and Research Centre, Zaria, Nigeria.

\section{Patients}

During the period May 1982 to April 1984, 5 patients with chronic ulcers over hands and feet with a malignant transformation were treated at the Leprosy Control and Research Training Centre, Zaria, Nigeria. These 5 black African males form the basis of this report.

Case 1. A 45-year-old male shepherd with BT leprosy gave a history of recurrent ulceration over the left heel for the past 20 years. It became persistent during the past 2 years. The heel showed a $15 \mathrm{~cm}$ diameter hypertrophic ulcer without any regional adenitis. Histology of the ulcer revealed a verrucous carcinoma. The patient is doing well to date following a below-knee amputation done 16 months ago.

Case 2. A 60-year-old trader with BT leprosy had persistent ulceration of the 
left heel for 10 years. It became hypertrophic in the past 3 years. The ulcer measured $6 \times 8 \mathrm{~cm}$ and there were a few small non-tender lymphnodes in the groin. Biopsy of the ulcer showed squamous cell carcinoma. A below-knee amputation was done 17 months ago and he is doing well.

Case 3. A 43-year-old male with LL leprosy had a $12 \mathrm{~cm}$ diameter hypertrophic ulcer of the middle of the sole of his right foot for 10 years. There were a few small non-tender lymphnodes in the right groin. Biopsy of the ulcer showed squamous cell carcinoma. A below knee amputation was done. One month following the amputation the patient died with a large ulcerating mass in his right groin.

Case 4. A 70-year-old male with BT leprosy presented with a $4 \times 5 \mathrm{~cm}$ hypertrophic, hyperaemic ulcer of his left palm of 4 years duration (Figure 1 ). The ulcer was said to have developed after a 15 kilometer bicycle ride and was persistent. Rubbery tender nodes were palpable in the left axilla. Biopsy of the ulcer revealed verrucous carcinoma (Figure 2). A below-elbow amputation was done 3 months ago and the patient is well up to the time of writing.

Case 5. A 55-year-old male having BT leprosy reported with a $14 \times 8 \mathrm{~cm}$ ulcer on the postero-lateral aspect of his left heel of 2 years duration. It started as a hard nodule 2 years ago and the patient pricked it thinking it was a thorn blister. It had been growing since then. The ulcer was hypertrophic with nodular margins overhanging the edges, projecting $3 \mathrm{~cm}$ above the level of the surrounding skin. Multiple intracutaneous nodules over the lateral aspect of the left leg, presumably secondary deposits, were also present (Figure 3). The left groin showed a $8 \times 6 \mathrm{~cm}$ clump of lymph nodes. Biopsy of the ulcer revealed squamous cell carcinoma

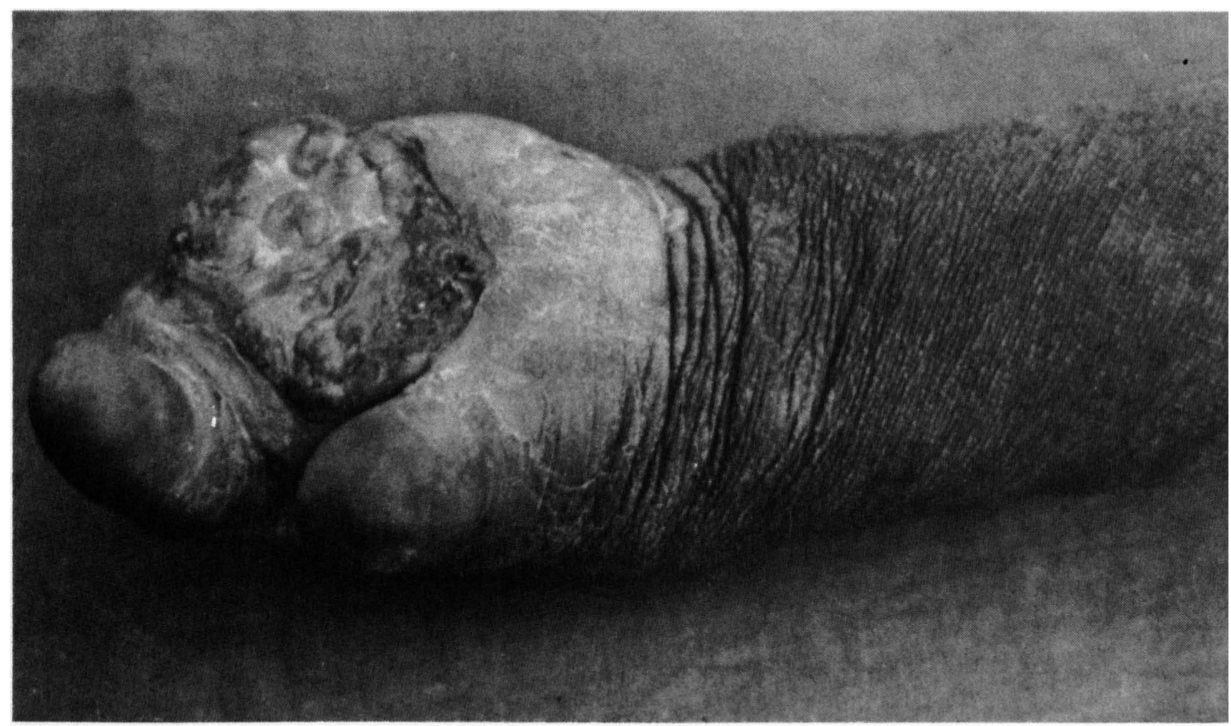

Figure 1. Hypertrophic ulcerating mass over the deformed palm of Case 4. 


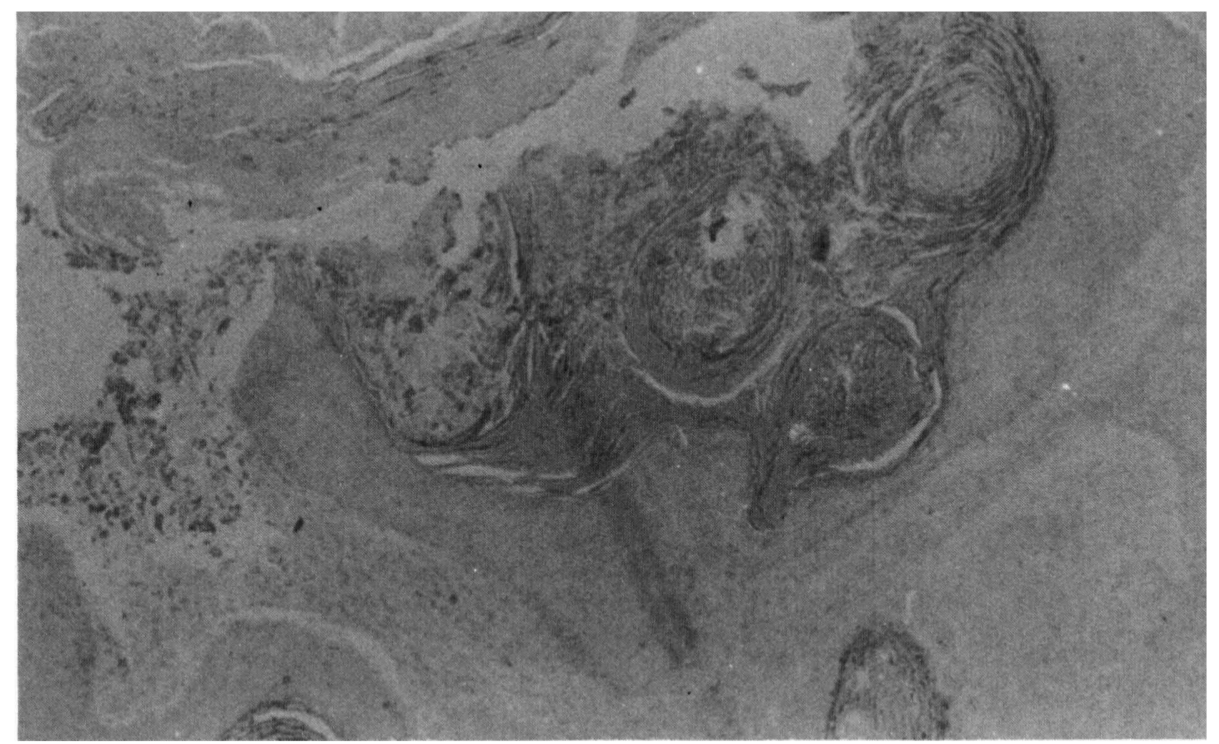

Figure 2. Biopsy of the same patient as in Figure 1, shows large cysts filled with keratin flakes in the malignant squamous epithelium: verrucous carcinoma. $(\mathrm{HE} \times 40)$.

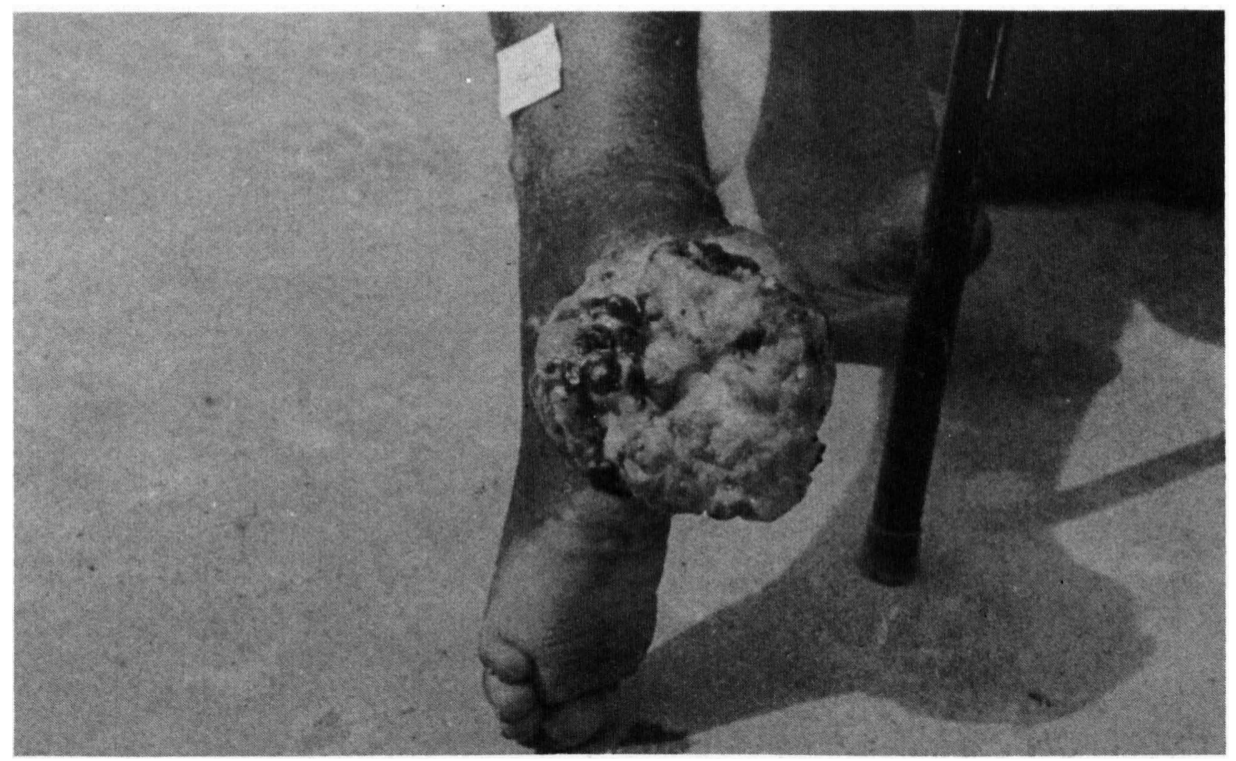

Figure 3. Cauliflower-like growth over the left heel of Case 5 with hacmorrhagic surface. 


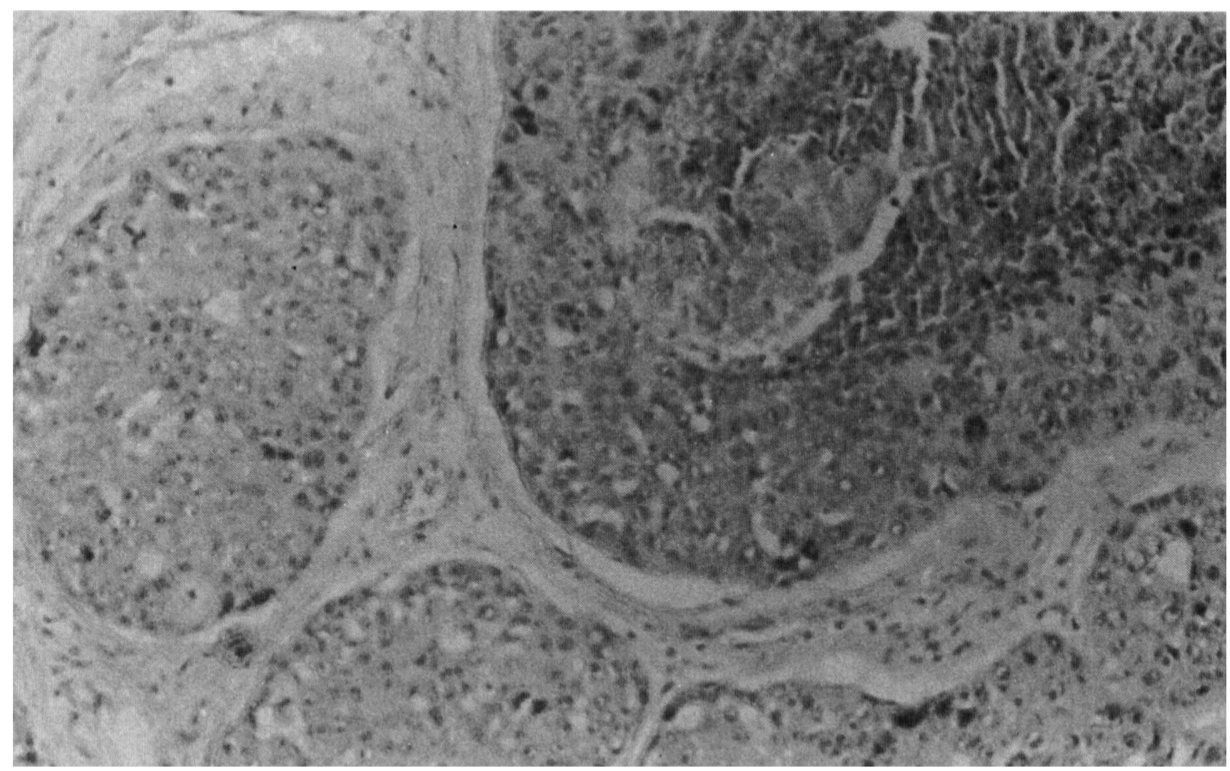

Figure 4. Multiple islands of malignant squamous epithelial cells infiltrating deep into the connective tissue, Case $5(\mathrm{HE} \times 400)$.

(Figure 4). A palliative left below-knee amputation was done 9 weeks prior to the compilation of this manuscript and the patient is well so far.

\section{Discussion}

Squamous cell carcinoma is a frankly malignant epithelial tumour arising from epidermal cells. It is more common in males in the older age group. There are many predisposing factors like solar irradiation, leucoplakia, Bowen's disease, burn scars, xeroderma pigmentosa etc, including chronic ulcers of the skin.

Leprosy predisposes to some malignancies' but cancer development in chronic trophic ulcers is rare. ${ }^{24}$ Though chronic trophic ulcers over hands and feet are very common in leprosy, this malignant transformation is so rare as to be still presented as single case reports. ${ }^{5}$

The usual squamous cell carcinoma merits no special histological description. Verrucous carcinoma is its variant with very slow growth, poor invasive nature and good prognosis. Histologically it is characterized by large keratin filled cysts.

Among the 5 cases currently being reported, 4 were plantar ulcers. The one found on the palm is distinctly rare and we were not able to find such a report in literature. All the cases reported to the hospital after several years of persistent ulceration. The fact that the duration was long and 3 out of 4 were verrucous type, indicates that the prognosis is good. Depressed cell-mediated immunity in Case 3 
with LL leprosy might have contributed both to the development of the carcinoma and early death due to metastasis.

Detection of 5 cases in this centre in a brief period of 2 years indicates that it is not so rare. One should specifically look for it in chronic ulcers so that treatment can be given early and adequately.

\section{References}

1 Purtilo DT, Pangi. Incidence of cancer in patients with leprosy. Cuncer, 1975; 35: 1259-61.

2 Job CK, Riedel GG. Squamous cell carcinoma arising in plantar ulcers in leprosy. Int $J$ Lepr, 1964; 34: 37-44.

${ }^{3}$ Michael J. Malignant tumours of the skin among leprosy patients. Int J Lepr, 1966; 34: 274-86.

${ }^{4}$ Andersen JG. Malignant degeneration in chronic ulceration of the leg and foot in leprosy patients, two case reports. Lepr Rer, 1982; 53: 265-9.

5 Ramadan WM. Epithelioma cuniculatum, poster presentation. $12^{\text {th }}$ International Lepros.' Congress, New Delhi, 1984. 